\title{
Paisagem urbana, espaços públicos e a gestão territorial em cidades médias paulistas: reflexões a partir de São Carlos, SP,
} Brasil

\author{
Paisaje urbano, espacios públicos y la gestión territorial en \\ ciudades medias de São Paulo: reflexiones para el caso São \\ Carlos, SP, Brasil
}

\section{Urban landscape, public spaces, and territorial management in medium-sized cities in São Paulo: reflections from São Carlos, SP, Brazil}

\author{
Renata Bovo Peres \\ renataperes@ufscar.br \\ Universidade Federal de São Carlos, UFSCar, São Carlos, SP \\ Sandra Regina Mota Silva \\ sandra.regina.mota.silva@gmail.com \\ Universidade Federal de São Carlos, UFSCar, São Carlos, SP
}

Luciana Bongiovanni Martins Schenk

lucianas@sc.usp.br

Universidade de São Paulo, USP, São Paulo, SP

\begin{abstract}
Resumo: Discute-se neste trabalho as relações entre paisagem urbana, espaços públicos e a gestão territorial numa cidade média paulista. Três conjuntos de abordagem são delineados: o estabelecimento de parâmetros para a caracterização das cidades médias paulistas; o contexto específico de São Carlos, com características biofísicas conjugadas à dinâmica socioespacial de desenvolvimento e expansão, e os desafios e perspectivas na configuração e gestão dos espaços livres públicos e paisagens urbanas. Propõe-se refletir sobre articulações entre os campos dos planejamentos da paisagem e urbano e indicar aplicações ao contexto estudado, com integrações entre desenho, instrumentos, legislações e políticas públicas.
\end{abstract}

Palavras-chave: sistema de espaços livres; planejamento da paisagem; gestão urbana.

Resumen: En este trabajo fueron discutidas las relaciones existentes entre paisajes urbanos, espacios públicos y la gestión territorial de una ciudad de medio porte paulista. Fueron definidas tres temáticas a abordar: el establecimiento de parámetros para la caracterización de las ciudades de medio porte en el estado de São Paulo; el contexto especifico de São Carlos considerando las características biofísicas a la dinámica socio espacial de desarrollo y expansión; y, los desafíos y perspectivas de la configuración y gestión de los espacios libres públicos y paisajes urbanos. De esta forma, se pretende reflexionar sobre posibles articulaciones entre los campos de ordenamiento del paisaje y ordenamiento 
urbano, indicando aplicaciones al contexto estudiado que integren diseño, instrumentos, legislaciones y políticas públicas.

Palabras clave: Sistema de espacios libres; ordenamiento del paisaje; gestión urbana.

\begin{abstract}
This paper discusses the relationships between urban landscape, public spaces, and territorial management in one medium-sized city of São Paulo state. Three sets of approach are outlined: the establishment of parameters for the characterization of the medium-sized cities of São Paulo; the specific context of São Carlos, with biophysical characteristics conjugated with the socio-spatial dynamics of development and expansion; and the challenges and perspectives in the configuration and management of public spaces and urban landscapes. It is intended to reflect on articulations between the fields of landscape and urban planning and indicate applications to the studied context, with integrations between design, instruments, legislation and public policies.
\end{abstract}

Keywords: free space system; landscape planning; urban management.

\title{
INTRODUÇÃO
}

Os espaços públicos nas cidades, especialmente aqueles destinados ao Sistema de Espaços Livres - SEL (ruas, praças, parques, etc.), têm um papel fundamental na composição da paisagem urbana e, como tal, têm também influência no bem viver de suas populações. Contudo, muitas dessas áreas enfrentam problemas de degradação e de subutilização, em função de um conjunto de fatores que envolvem mudanças culturais, políticas adequadas, ausência de atrativos e conectividade com seu entorno e o aumento da insegurança e da violência urbana, dentre outras razões enunciáveis, a depender do contexto. Tais condições têm como uma de suas decorrências, a busca de opções em espaços privados ou fechados ao acesso público, especialmente nas faixas de renda com maior poder aquisitivo que, na atualidade, optam por alternativas que expressam experiências de pouca ou nenhuma mistura social, especialmente as relacionadas à esfera pública.

A ideia de pensar os espaços livres a partir de uma abordagem sistêmica vem sendo reconhecida como uma referência e uma base metodológica para se propor o planejamento e um desenho urbano que possam contribuir com a complexa perspectiva contemporânea, tomando como aspectos e parâmetros: a conectividade da paisagem; a biodiversidade e os serviços ecossistêmicos; a integração de infraestruturas e sistemas urbanos (SPIRN, 1995; BENEDICT; MCMAHON, 2006); a questão do conforto ambiental e as relações entre o uso dos espaços livres e melhorias na saúde da população (CARRUS et al., 2015; SALDIVA, 2018).

Enfatiza-se nesse esforço uma estratégia fundamental de valorização da vida e criação de lugares, alicerçada no uso público e na criação de paisagens relacionadas a aspectos históricos e socioculturais (MACEDO, 2012; MACEDO; CUSTÓDIO; DONOSO, 2018).

Produzir, portanto, novas reflexões relacionadas aos espaços livres públicos em cidades brasileiras requer compreender a trajetória histórica à qual se liga essa perspectiva de planejamento com a paisagem, e seus desdobramentos atuais, considerando a importância 
de projetos e políticas voltadas ao atendimento das demandas atreladas a essas áreas, que devem ser planejadas incorporando características e potencialidades locais.

Procura-se discutir nesse trabalho a importância dos espaços livres públicos livres de edificação, em especial praças e parques, ruas e avenidas, na composição e caracterização da paisagem e na qualificação da vida urbana, com o intuito de identificar entraves e potencialidades que forneçam subsídios à formulação de instrumentos, medidas ou recursos aplicáveis nas políticas públicas afetas à valorização desses espaços. Busca-se compreender, em especial e como recurso metodológico, o trânsito de escalas, do plano ao desenho urbano, sua construção e apropriação. Os processos atuais de produção, apropriação e expansão da cidade, afetam não apenas a cidade constituída, mas também os contornos periurbanos e rurais, e vêm conformando potenciais espaços públicos e transformando a paisagem.

As cidades médias paulistas foram adotadas como universo de investigação, pois apresentam um conjunto de particularidades morfológicas, econômicas e socioespaciais. Dentro desse contexto, o objeto empírico específico foi o município de São Carlos, o qual apresenta um Sistema de Espaços Livres fragmentado, desconectado e com identidade pouco reconhecida pela população. Segundo Peres (2012), a ausência de incorporação da realidade desses espaços pelas gestões municipais ao longo do tempo, principalmente pela desvalorização de políticas e ações de planejamento, construiu um território urbano em conflito com o meio físico e carente de espaços livres de qualidade, qualificados para o uso e fruição da população e capazes de dar suporte à biodiversidade urbana (RUMBLE et al., 2019).

Para Schenk, Peres e Fantin (2018), questões técnicas e legais de mitigação dos problemas poderiam receber tratamento de maior fôlego, articulando espaços e constituindo uma rede de lugares que operassem nas duas dimensões que fundamentam o campo disciplinar da Paisagem: infraestrutural e de convívio social, fruição e contemplação. As condições de impermeabilização e baixa arborização têm potencialidades para serem alteradas e associadas à rede de reservas ligadas aos córregos, de modo a constituir um Sistema de Espaços Livres de maior complexidade socioambiental.

Grande parte das áreas públicas urbanas dessa realidade de cidades médias, advêm dos processos de parcelamento do solo. No Brasil, a partir da Lei Federal 6.766 de 1979, todo parcelamento do solo urbano deve destinar um determinado percentual da gleba empreendida para uso público. Em seu texto original, a lei previa um percentual mínimo de $35 \%$, redistribuídos entre o sistema de circulação, áreas para implantação de equipamentos urbanos e comunitários e áreas para espaços livres, devendo ser proporcionais à densidade de ocupação prevista para a gleba (BRASIL, 1979). Todavia, em consonância com o processo de municipalização da legislação afeita ao planejamento e à gestão territorial, a Lei Federal 9.785 de 1999, estabeleceu a esfera municipal como responsável por tais definições, mantidos os $35 \%$, amparada nos dispositivos legais dispostos em seus planos diretores ou em suas leis de parcelamento, uso e ocupação do solo (BRASIL, 1999).

Na cidade de São Carlos, de acordo com seu Plano Diretor Municipal, atualizado em 2016, o percentual de áreas públicas é de 18\% (exceto o sistema de circulação), divididos 
entre Sistema de Lazer (7\%), Uso Institucional (7\%), e Uso Patrimonial (4\%), com as seguintes atribuições de usos do Art. 132 (SÃO CARLOS, 2016):

a) Sistema de Lazer: área destinada ao sistema de áreas livres públicas, visando à implantação de praças, parques, áreas com equipamentos de lazer, culturais ou esportivos, como playgrounds, quadras, campos de jogos, dentre outras;

b) Área Institucional: área pública destinada à implantação de edificações e/ou equipamentos públicos ou de uso comunitário;

c) Área Patrimonial: área pública que integrará o patrimônio municipal sem afetação de uso, a não ser no caso de destinação da mesma à Fração de Interesse Social, podendo ser destinadas a usos de interesse público, social ou comunitário, e sendo vedada a venda da mesma

Esse percentual pode ser considerado relevante na composição morfológica de desenho urbano da cidade, uma vez que os empreendimentos dispõem de um significativo potencial para contribuir com uma inserção qualificada na paisagem da cidade. Contudo, não basta que tais valores nominais sejam cumpridos, mas que a configuração do desenho urbano resultante do empreendimento favoreça sua valorização urbanística e ambiental, dotando tais áreas de um potencial de interação em várias escalas, desde as relações que estabelecem entre si, passando pelos espaços do próprio empreendimento até as demais áreas urbanas contíguas.

Atualmente a cidade possui, em seu limite urbano, 863 áreas públicas, dentre elas 265 classificadas como áreas de uso institucional e 598 como sistema de lazer, perfazendo um total de $4,8 \mathrm{~km}^{2}$, o que equivale a cerca de $5,6 \%$ do perímetro urbano atual (SÃO CARLOS, 2016).

Apesar de prever a dotação de áreas públicas na implantação de projetos de loteamentos, a Lei 6.766/1979 nada dispôs acerca da responsabilidade de desenvolvimento de projetos para essas áreas que passavam à responsabilidade do município, na consecução dos registros cartoriais do empreendimento. Trata-se de uma questão que foi tratada de modo quantitativo e não qualitativo o que teria promovido a permanente incompletude nos empreendimentos, como argumenta Santoro

Se a lei federal não foi crítica em relação à completude de uma "urbanização primária" (infraestrutura), e deixou aos municípios o dever de fazer a "urbanização secundária" (equipamentos e serviços), geralmente muito demorada, terminou por garantir, na realidade, uma "urbanização incompleta" (SANTORO, 2012, p.333).

No Brasil, embora tenha havido recentes avanços na legislação afeta à política urbana e ambiental, a maioria das cidades não dispõe de mecanismos jurídicos e administrativos, ou mesmo instrumentos técnicos de planejamento urbano, capazes de nortear projetos de parcelamento, uso e ocupação do solo, com vistas à constituição de um sistema de espaços públicos qualificados para dotar as cidades de paisagens urbanas integradas e articuladas (SILVA; BUENO, 2018). 
Nesse sentido, há uma lacuna instalada, e que envolve recursos e instrumentos da política urbana e ambiental, que contribuam na qualificação de projetos urbanos decorrentes de empreendimentos que parcelam o solo, sejam eles via desmembramentos, loteamentos ou espaços condominiais. Embora a maioria dos empreendimentos condominiais tenha qualidade em seus espaços internos, livres e abertos, são áreas coletivas intramuros que respondem às estratégias de atratividade de um novo morar, reforçadas nas campanhas publicitárias de valorização de um produto imobiliário em expansão. Nesse sentido, Martins alega que esse modelo traz algumas consequências:

Esse padrão, associado a imagens produzidas pelo marketing imobiliário e à escalada da violência urbana, construiu um padrão de moradia que nega o espaço público, a urbanidade e a diversidade dos centros urbanos [...] engendra o abandono de alternativas formais que poderiam viabilizar melhor qualidade urbana e ambiental (MARTINS, 2012, p.162).

Rodrigues, Silva e Gonçalves (2018) argumentam que desde os anos 1960, Jane Jacobs (2009) já defendia a ampliação da segurança urbana atrelada à vitalidade social decorrente da diversidade de usos e da mescla de atividades que impulsionem a permeabilidade das fachadas junto aos passeios públicos, promovendo o compartilhamento, os encontros e as vivências sociais. Essa proposta é o avesso da tendência de proliferação dos empreendimentos condominiais murados nas periferias urbanas, processo comum nas cidades médias brasileiras que geram extensos muros de isolamento na paisagem.

A relação dos espaços condominiais com o ambiente exterior é de isolamento, como 'enclaves fortificados' (CALDEIRA, 2000), oferecendo na interface pública, uma paisagem caracterizada pela aridez e monotonia de extensas áreas cercadas, por muros ou grades integrantes do sistema de controle de acesso e de segurança interna. Para o meio externo há perda de qualidade e de segurança que só os usos diversificados conseguem promover. O contraponto a esse isolamento tem sido o conceito de "fachadas ativas" como elemento agregador da vida urbana, intensificando a vitalidade das calçadas ao ampliar o diálogo entre o lote (esfera privada) e os espaços externos (esfera pública) (GEHL, 2013; SÃO PAULO, 2014; WRI BRASIL, 2018).

Além dos condomínios de acesso controlado, outra paisagem comum às franjas periféricas das cidades médias paulistas são os extensos conjuntos habitacionais de interesse social com precariedade de solução projetual, em especial seus espaços livres e de sua inserção urbana. O processo de produção de cidade, nessas áreas de expansão urbana, configura políticas habitacionais destinadas a diferentes estratos sociais e, nos dois extremos, terminam por comprometer as possibilidades de qualificação da paisagem urbana sob a perspectiva estético cultural, ambiental e pública (SILVA et al., 2015; SPOSITO; GÓES, 2013; VASCONCELOS; CORRÊA; PINTAUDI, 2013).

Tais temas e argumentos revelam preocupações diante da falta de qualidade na maioria desses espaços, fruto de diretrizes da esfera pública em sua concepção, e que se mantém dela dependentes no que diz respeito à sua gestão e manutenção. 
Embora os avanços na legislação urbanística e ambiental, das últimas quatro décadas, sejam amplamente reconhecidos (SILVA, 2011), especialmente após a Lei da Política Nacional do Meio Ambiente - Lei Federal 6.938/1981 (BRASIL, 1981), do marco referencial da Constituição Federal de 1988 e do Estatuto da Cidade - Lei Federal 10.257/2001 (BRASIL, 2001), tais dispositivos legais não se traduzem, diretamente, enquanto configuração morfológica e de projeto, e enquanto possível expressão de atributos de desenho urbano qualificado.

Nesse sentido, para Martins há princípios expressos em diretrizes de desenvolvimento urbano e em planos diretores, porém,

...não se traduzem em forma urbana, pouco avançando no sentido de compreender melhor o enlace entre economia e produção do espaço urbano e, consequentemente, forma urbana. Enunciados nos vigentes "instrumentos de planejamento" e da "reforma urbana", colocam em foco objetivos quanto ao desenvolvimento urbano, mas estão longe de aproximar-se de qualquer imagem de configuração urbana. A cidade em sua forma física permanece com poucas utopias e sem uma forma física que expresse e materialize tais objetivos (MARTINS, 2012, p.157).

A falta de qualidade na maioria dos espaços públicos urbanos ocorre segundo duas vertentes principais: 1) nos espaços já constituídos e que se encontram assimilados na cidade consolidada e 2) nos novos espaços públicos que têm sido gerados a partir de empreendimentos mais recentes localizados nas bordas das ocupações urbanas, em área de transição com o espaço rural. Dentro de cada uma dessas vertentes há novos desdobramentos de configurações possíveis que permitem apresentar as interações estabelecidas entre esses espaços e suas áreas envoltórias.

A partir do problema colocado na discussão de introdução, esse trabalho tem como objetivo contribuir no processo de compreensão das relações entre paisagem urbana, espaços públicos e a gestão territorial na cidade média paulista de São Carlos. Para tal, o artigo foi subdividido em três conjuntos de abordagem: o estabelecimento de parâmetros para a caracterização das cidades médias paulistas; o contexto específico do município de São Carlos, com suas características biofísicas conjugadas à dinâmica socioespacial de desenvolvimento e expansão. No terceiro conjunto discutem-se desafios e perspectivas na configuração e gestão dos espaços livres públicos e paisagens urbanas.

Pretende-se, com isso, aprofundar reflexões e articulações entre os campos do planejamento da paisagem e do planejamento urbano e indicar aplicações ao contexto estudado, contribuindo com a inovação científica e metodológica, bem como com a proposição de instrumentos e políticas públicas.

\section{CARACTERIZAÇÃO DAS CIDADES MÉDIAS PAULISTAS}

Acerca do processo de urbanização brasileira, Milton Santos (1996) afirma, a partir da segunda metade do século XX, o notável crescimento do número de cidades com mais de 100 mil habitantes no território brasileiro. No período de 1950 a 2010, o número 
de municípios entre 100 mil e 500 mil habitantes salta de 35 em 1950, para 245 em 2010, produzindo um crescimento de $700 \%$ em 60 anos (IBGE, 2010).

Segundo Andrade e Serra (2001), nas últimas décadas, submetidas a diferentes contextos de distribuição, concentração e dispersão da população, foram produzidas classificações distintas do porte de cidades, apoiadas em argumentos acerca dos intervalos populacionais que compõem a pluralidade da rede urbana brasileira. $O$ consenso atual estabelece que, demograficamente, as cidades médias têm entre 100 mil e 500 mil habitantes.

O consenso produzido pelos especialistas de que a dimensão demográfica é necessária, porém insuficiente, amplia sua reflexão passando a incorporar, também, aspectos de ordem funcional dessas cidades (SANTOS, 1996; ANDRADE; SERRA, 2001; BRAGA, 2004; SPOSITO, 2004; CASTELLO BRANCO, 2006).

Sendo o critério populacional insuficiente, Santos propõe como critério adicional, um desempenho de ordem funcional como centro regional:

A expansão e a diversificação do consumo, a elevação dos níveis de renda e a difusão dos transportes modernos, junto a uma divisão do trabalho mais acentuada, fazem com que as funções de centro regional passem a exigir maiores níveis de concentração demográfica e de atividades (SANTOS, 1996, p.73).

Além do critério demográfico e funcional, outra condição utilizada para caracterizar tais cidades é não pertencerem às regiões metropolitanas.

Ao investigar as cidades médias paulistas, a geógrafa Maria Encarnação Beltrão Spósito (2004) destaca a relevância do caráter regional dessas cidades para a divisão territorial do trabalho, na articulação da rede urbana de sua área de influência, de tal modo que,

[...] no Estado de São Paulo, essas cidades são, de um lado, aquelas nas quais a população das cidades pequenas polarizadas por elas realiza o consumo de bens e serviços necessários à produção e à vida, e são, de outro lado, os espaços escolhidos para a localização das grandes empresas comerciais e de serviços que querem atingir um mercado consumidor de poder aquisitivo crescente no interior paulista (SPOSITO, 2004, p.126).

A partir dessas novas dinâmicas econômicas decorrentes do processo de globalização, Eliseu Savério Spósito (2006, p.45), destaca uma alteração de paradigma para interpretar esse território que incorpora as noções "de eixos de desenvolvimento, de aumento de novos empregos, de novas formas de produção e de população, em contraposição ao paradigma de área, que serviu para explicar o papel das cidades de porte médio em décadas passadas". Tais transformações exigiram redefinições do espaço urbano e do mercado de trabalho industrial:

[...] os municípios situados em áreas mais distantes da metrópole, com forte participação tecnológica motivada pela presença da universidade pública que gera pesquisas, têm no emprego industrial importante fator de indução ao seu próprio crescimento, enquanto que os municípios mais próximos da metrópole, com tradição da indústria conhecida como de tipo fordista, que entrou em crise a partir dos anos 
1970, tenderam a perder importância no emprego industrial no Estado de São Paulo (SPOSITO, 2006, p.44).

Como partes integrantes da reestruturação produtiva, a elevação da produtividade, a redução de custos e a ampliação dos mercados, deixou um conjunto de marcas na reconfiguração espacial econômica, dentre elas, o deslocamento da produção para outras regiões não metropolitanas.

Para Terci, Goulart e Otero (2017) as condições mais procuradas na interiorização da produção industrial contemplaram a disponibilidade de infraestrutura, mão de obra e matérias primas baratas, incentivos fiscais e qualidade de vida. Nesse processo, segundo os autores, as cidades se tornaram a célula jurídico/administrativa de maior interesse, levando à expectativa de que as gestões locais assumam condutas pró ativas e disponibilizem um ambiente urbano propício aos negócios, ensejando o 'empresariamento urbano' (HARVEY, 2005). Dessa forma, “as cidades são projetadas como a escala geográfica de maior relevância no capitalismo globalizado, conectando-se diretamente com os fluxos de negócios, esvaziando as funções da esfera federal" (TERCI; GOULART; OTERO, 2017, p.147).

Para Andrade e Serra (2001) podem ser admitidas três novas funções para as cidades médias, a partir dos processos desencadeados pela globalização: i) Cidades articuladoras privilegiadas nos eixos ou corredores de desenvolvimento; ii) Cidades com atuação nos sistemas de redes regionais ou nacionais; iii) Cidades com localização de tecnopolos. Tais fenômenos se tornaram, portanto, parte essencial nos esforços para compor a caracterização das cidades médias paulistas.

Essa modalidade de cidades, na qual se inclui São Carlos, a partir da década de 1970, tem apresentado taxas de crescimento populacional superiores às do Estado de São Paulo e do Brasil. Os conflitos e contradições socioespaciais, estruturais da realidade brasileira, também estão presentes em seus espaços urbanos, bem como nas suas relações articuladas entre as escalas municipais e regionais. Contudo, os efeitos dos conflitos não assumem ainda a dimensão das aglomerações metropolitanas. A expectativa de se promover alterações que aprimorem as condições urbanas e ambientais locais/regionais, ainda se coloca como uma possibilidade de realização a médio prazo, a depender das ações e políticas urbanas a serem concebidas, discutidas e implementadas.

Nessa perspectiva, os recursos da política urbana e os instrumentos integrantes dos processos de gestão da cidade consolidada e em expansão, que contribuam na qualificação de espaços públicos inseridos na dinâmica da vida urbana, adquirem ampla relevância para as práticas e reflexões do desenho e do planejamento urbano. 


\section{CONTEXTO URBANO E AMBIENTAL DE SÃO CARLOS}

\section{Dinâmicas, influências e articulações regionais e urbanas}

Localizada na região central do estado de São Paulo e pujante em crescimento econômico e demográfico, São Carlos possui população estimada de 249.415 mil habitantes (IBGE, 2018), distribuída em um território de 1.136,91 km²(Fig. 1). Distante 230 quilômetros da capital São Paulo, está conectada por importantes eixos rodoviários, como as rodovias Washington Luiz, Bandeirantes e Anhanguera.

Figura 1: Divisões regionais/municipais consolidadas envolvendo São Carlos, SP.
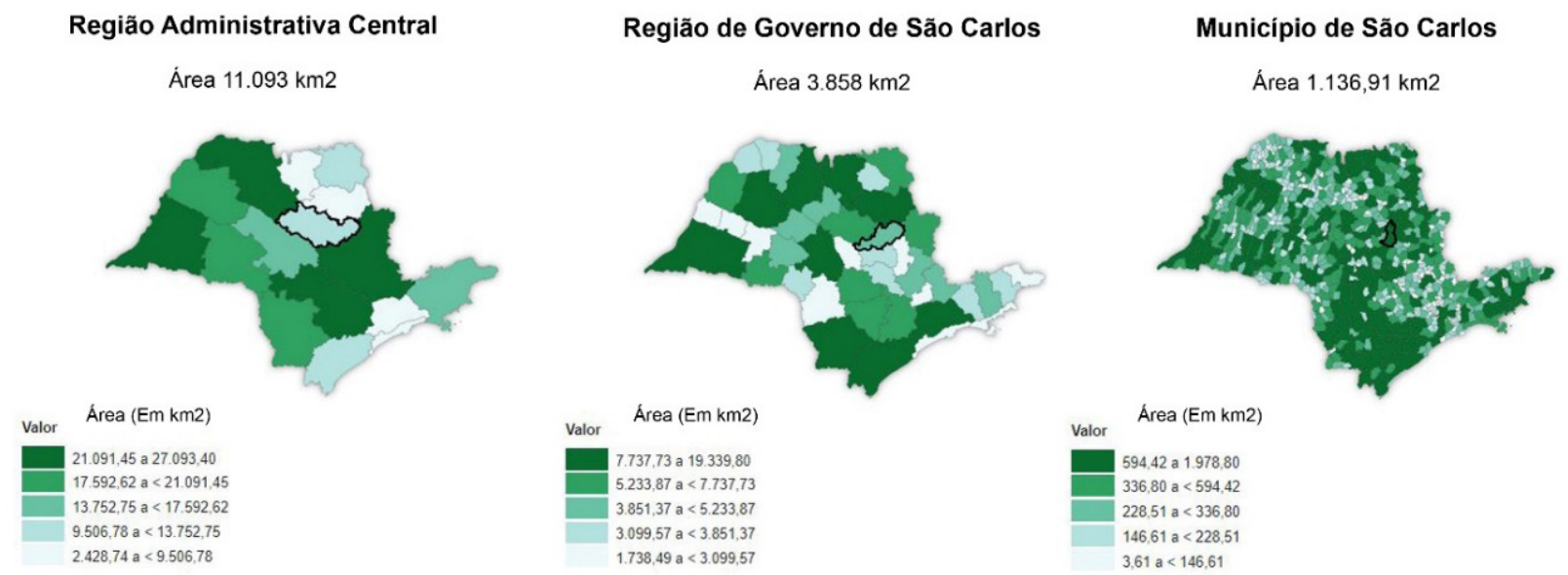

Fonte: IBGE; Fundação Seade, 2019.

A importância regional de São Carlos deve-se, sobretudo, a dois fatores. O primeiro deles refere-se à sua economia fundamentada em atividades industriais, onde destacam-se empresas, nacionais e multinacionais. A atividade agropecuária também contribui para a economia, porém com novas tendências. A produção de leite e as lavouras permanentes (como a laranja) estão sendo substituídas pela lavoura temporária (prioritariamente cana-de-açúcar).

O segundo fator que caracteriza São Carlos como influência regional, é o seu potencial universitário, envolvendo dois campi da Universidade de São Paulo (USP), um campus da Universidade Federal de São Carlos (UFSCar), o Instituto Federal de São Paulo (IFSP), a FATEC, e o Centro Universitário Central Paulista (UNICEP), além de duas unidades de pesquisa da Embrapa. Essas instituições abrangem uma comunidade acadêmica composta por mais de trinta mil pessoas. Como consequência, estudos realizados pela FAPESP (2016), indicam São Carlos como principal polo de empresas de base tecnológica do Estado de São Paulo, por ser uma cidade conectada com redes globais de conhecimento e de inovação.

Análises recentes realizadas pelo IBGE (2016) sobre os processos de urbanização e suas relações econômicas e sociais, definem a região de São Carlos como uma "média concentração urbana", cujos critérios empregam a noção de integração, medida pelos 
movimentos pendulares para trabalho e estudo ou a contiguidade urbana, que sintetizam "novas articulações regionais" (IBGE, 2016, p.4).

Ainda em escala regional, áreas urbanas de outros municípios contíguos, como Ibaté, fazem fronteira com o principal vetor de expansão de São Carlos sentido noroeste (Fig. 2), configurando uma tendência à conurbação, característica merecedora de atenção nos processos de planejamento da dinâmica espacial da expansão. Essas identificações de tendências à junção de estruturas urbanas, extrapolando limites político-administrativos, permite prever a ocorrência de novos arranjos populacionais, com desdobramentos nas formas de acesso à infraestrutura urbana, aos equipamentos e serviços públicos, nos vínculos socioeconômicos e nas lógicas espaciais.

Figura 2: Novas articulações regionais envolvendo São Carlos, SP.

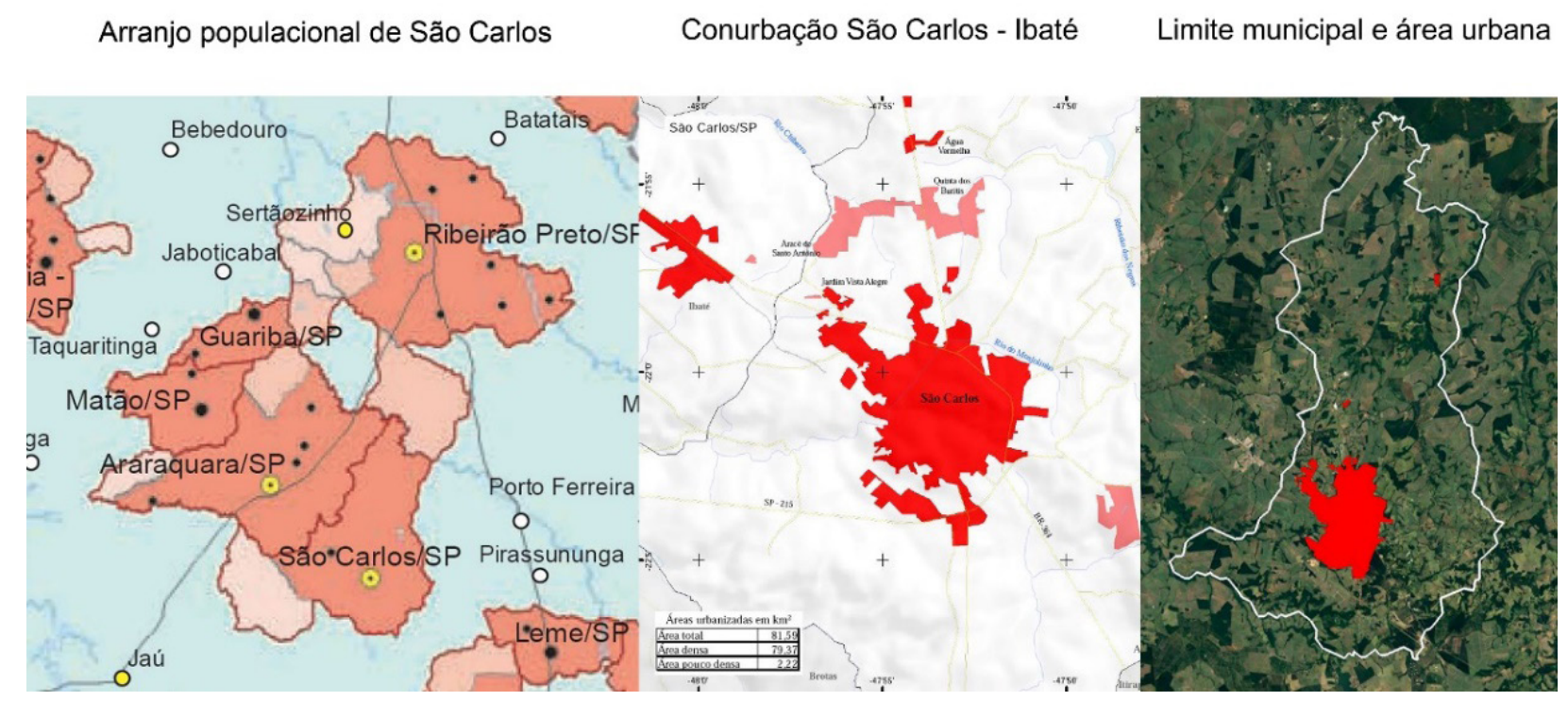

Fonte: IBGE, 2016a.

Todas essas características configuram São Carlos como uma cidade média do interior paulista que polariza e exerce influência regional, e que simboliza as políticas de interiorização da indústria do Estado de São Paulo, que foram facilitadas por "uma rede de centros urbanos de tamanho médio, por certa tradição industrial e pela existência de uma rede estadual de centros de pesquisa e ensino distribuídos por várias cidades" (DINIZ, 1993, p.50). Elas também vêm interferindo diretamente na morfologia e nas transformações da paisagem. Procurar compreendê-las, portanto, representa um aspecto fundamental aos processos de desenho, planejamento e gestão do território.

\section{Aspectos biofísicos relevantes conjugados à dinâmica socioespacial de desenvolvimento e expansão}

As características biofísicas do território de São Carlos, localizado na província geomorfológica das cuestas basálticas, distinguem especiais características de ocupação e 
revelam uma geografia (Fig. 3) que torna a paisagem desse trecho do Estado uma experiência memorável (SCHENK, PERES, FANTIN, 2018).

Figura 3: Paisagem urbana e periurbana de São Carlos, SP.

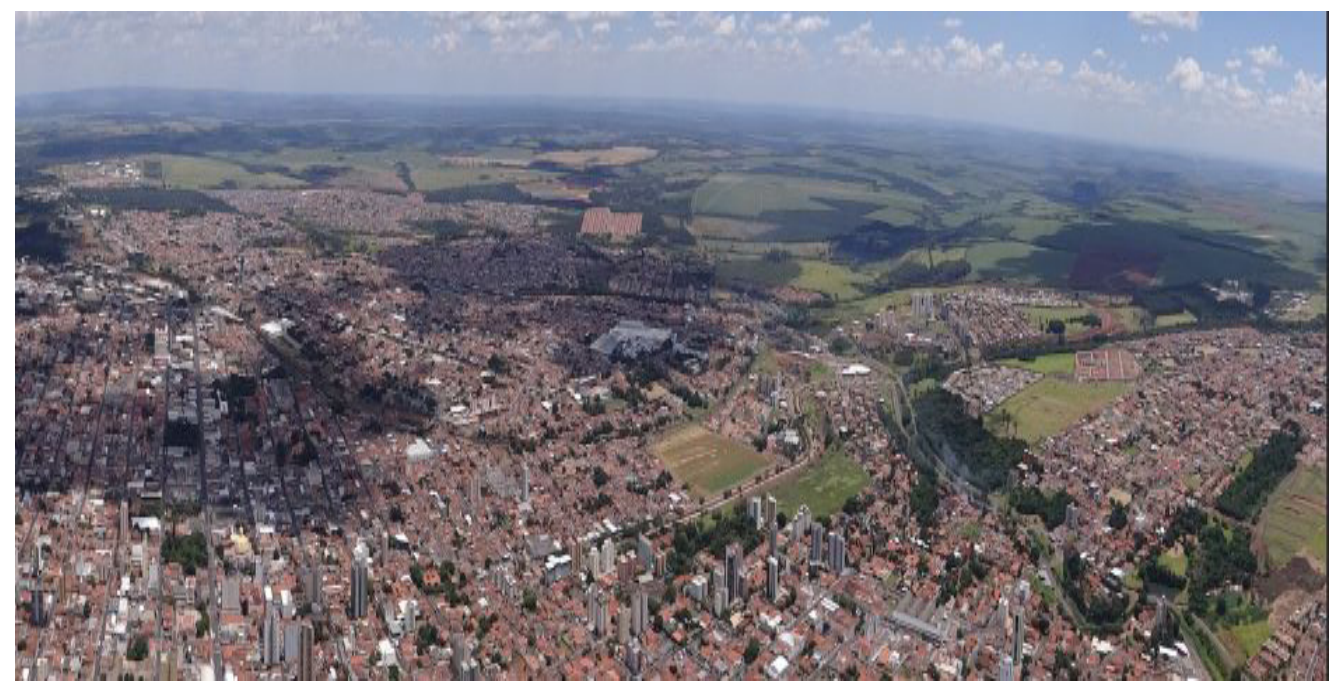

Fonte: QUAPÁ, 2014.

Uma delas é presença de significativos maciços vegetais compostos, sobretudo, por remanescentes do Cerrado Paulista e Floresta Estacional Semidecidual. Outras importantes áreas de preservação ambiental e de turismo ecológico marcam a região, como a APA Corumbataí, a Represa do Broa e três Estações Ecológicas.

Recentemente, o Ministério do Meio Ambiente (MMA, 2016) republicou Áreas Prioritárias para a Conservação, Utilização Sustentável e Repartição dos Benefícios da Biodiversidade (Fig. 4) que, novamente, indicou a porção centro-sul da cidade de São Carlos, como uma área de 'muito alta' prioridade para a conservação.

Figura 4: Biomas e Áreas Prioritárias para a Conservação da Biodiversidade com destaque (em quadrado preto) para a região de São Carlos, SP.
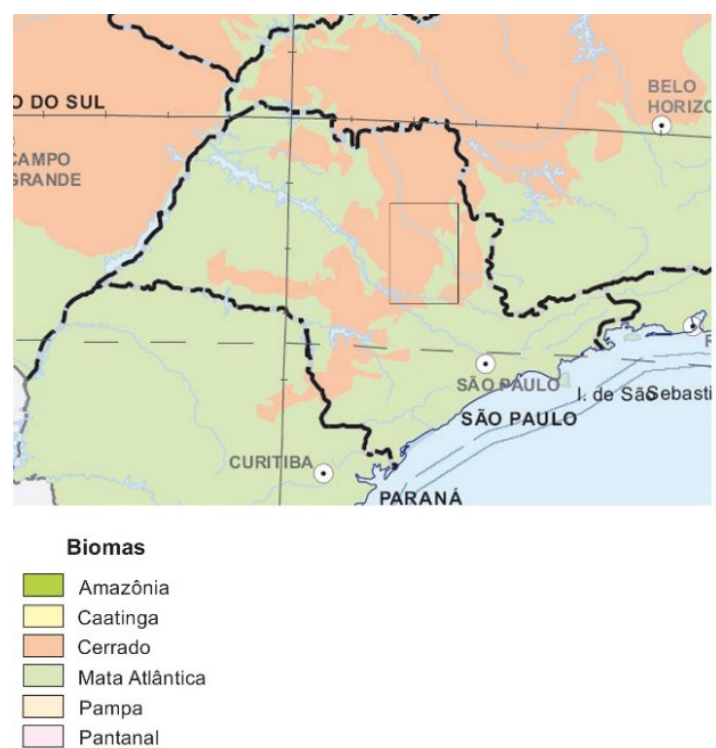
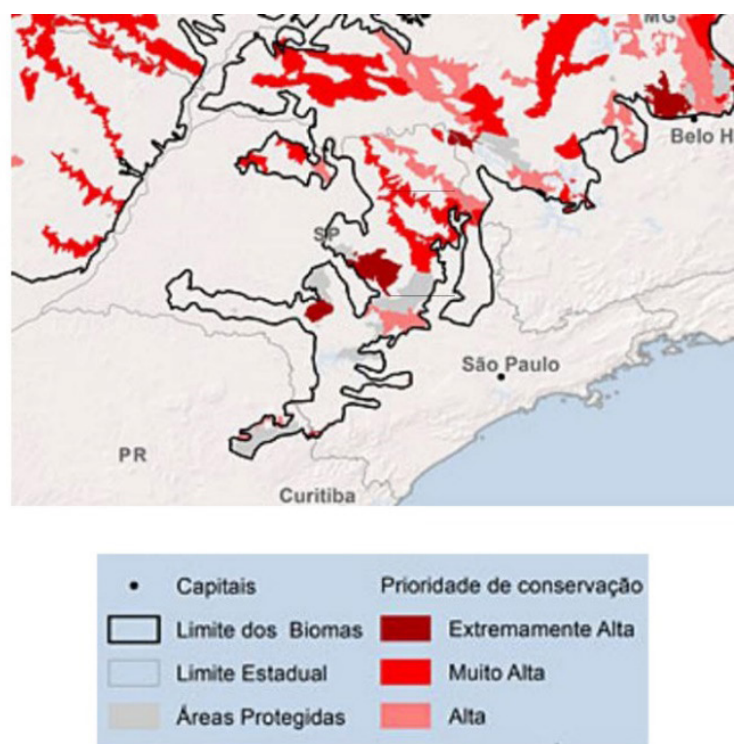

Fonte: IBGE, 2016b; MMA, 2016. 
A despeito destes estudos de relevância nacional, o total de fragmentos de vegetação nativa de São Carlos (Fig. 5) equivale a 19,3\% do território municipal (TREVISAN, 2015; MAZZUCO et al., 2018) e vem sendo reduzido.

Análises de Trevisan (2015) verificam que as áreas de vegetação nativa no município de São Carlos são dispersas e fragmentadas e reduziram cerca de 30\% nos últimos dez anos. Essa vegetação está sendo substituída, sobretudo, pela cultura da cana-de açúcar (que atualmente abrange $66,4 \%$ do território, entre áreas plantadas e solo preparado), acentuando o processo de fragmentação da paisagem em decorrência deste tipo de ação antrópica.

Em escala intraurbana, estudos realizados por Viana (2013) demonstram que $26 \%$ da área urbana são cobertos por vegetação arbórea, porém a distribuição no território é muito irregular e desigual.

A geologia do município de São Carlos (Fig. 5) está distribuída em seis tipos distintos, sendo a formação Botucatu a que mais se destaca, composta por arenitos finos e médios, e correspondente à área de recarga do Aquífero Guarani, maior manancial de água doce subterrânea transfronteiriço do mundo. Essas áreas estão sendo altamente afetadas pelos processos agrícolas já mencionados e, também, pelos processos de urbanização com alta impermeabilização do solo e contaminação em áreas de recarga.

Figura 5: Usos do solo, Hipsometria e Geologia de São Carlos, SP.

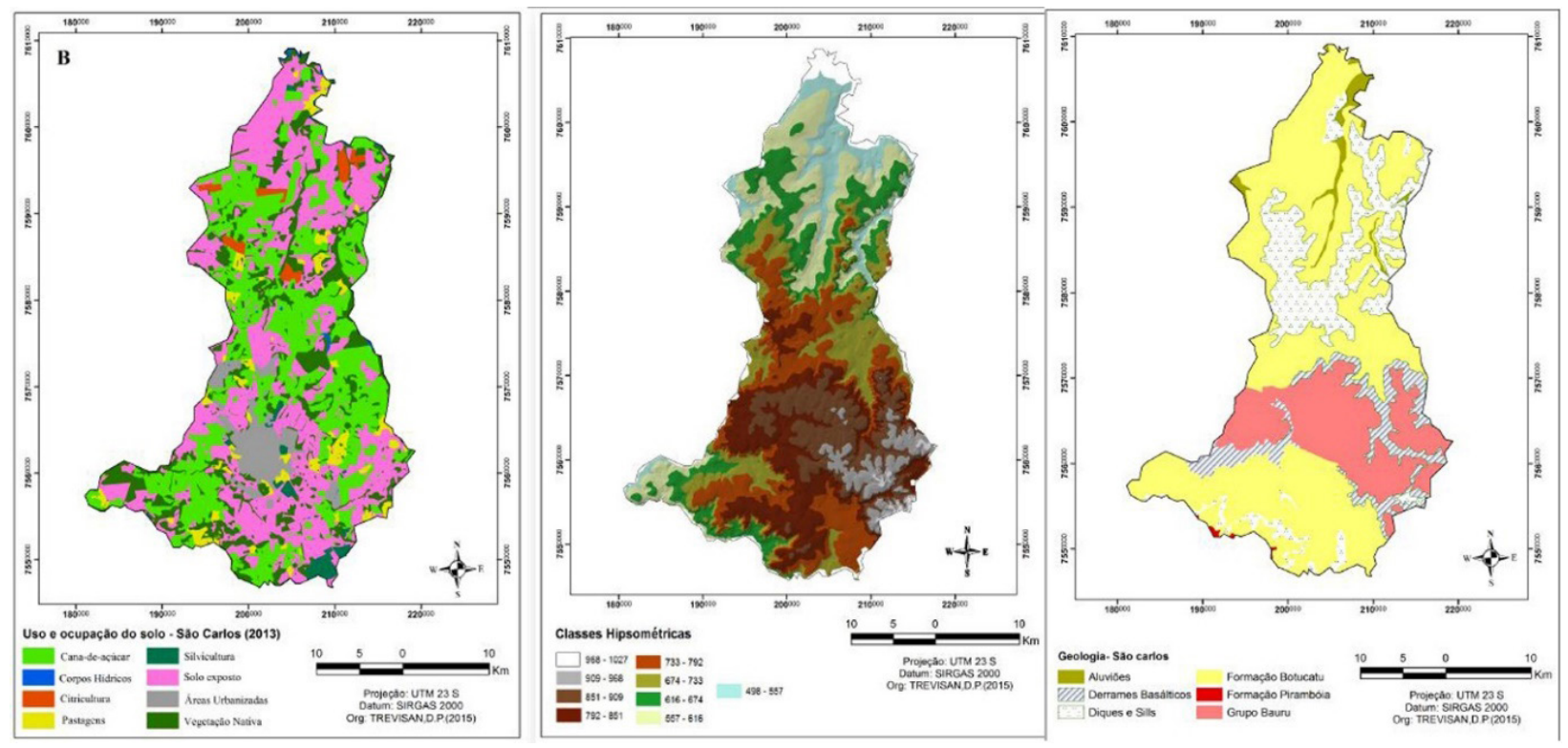

Fonte: TREVISAN, 2015; MAZZUCO et al., 2018.

Outro aspecto relevante de São Carlos é a sua considerável estrutura hídrica (Fig. 6). O município está inserido entre duas Unidades Hidrográficas de Gerenciamento de Recursos Hídricos do Estado de São Paulo (UGRHI): a nº 9, Mogi-Guaçu, e a nº 13, TietêJacaré. Esta última incorpora a maior parte da área urbana, que tem como corpo hídrico principal, o rio Monjolinho. Ainda em termos hídricos, a porção leste do município possui duas Áreas de Proteção e Recuperação de Mananciais - APREM: a Bacia Hidrográfica 
do rio Monjolinho, à montante, e a Bacia Hidrográfica do Ribeirão Feijão. Estas áreas conseguiram receber tratamento diferenciado nas legislações locais, que priorizaram as funções de preservação ambiental e de abastecimento público, com faixas de proteção e índices de uso e ocupação do solo mais restritivos do que outras regiões de planejamento. São fatores que condicionam conflitos com agentes ligados aos interesses do mercado e da expansão imobiliária.

Figura 6: Rede Hídrica e Bacias Hidrográficas de São Carlos, SP.
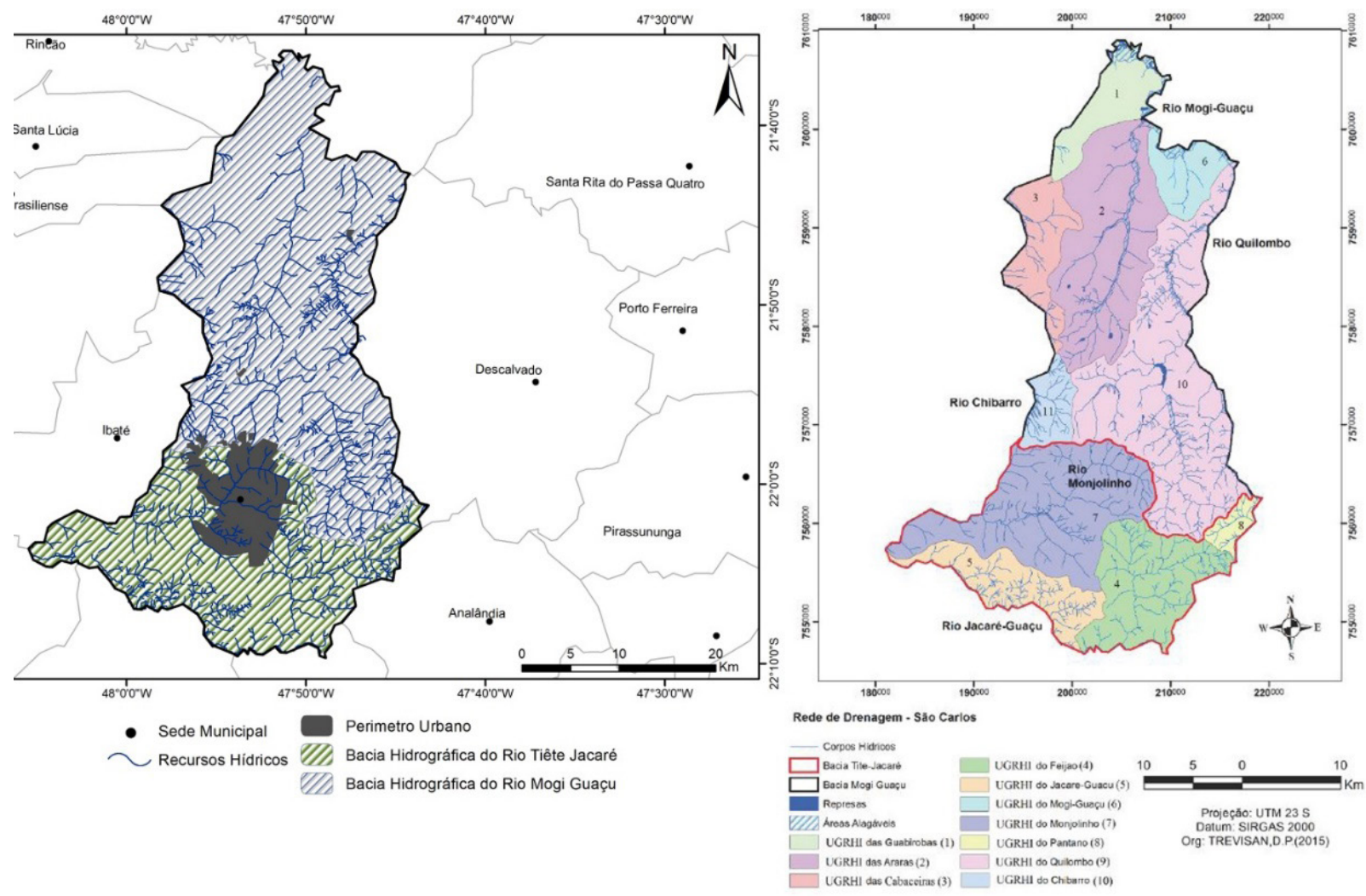

Fonte: TREVISAN, 2015; MAZZUCO et al., 2018.

Todas essas condições biofísicas vêm sendo continuamente afetadas e impactadas pelo modelo de ocupação urbano, periurbano e rural do município, com supressão de fragmentos vegetais, interferência e comprometimento de corpos hídricos e áreas de recarga de aquíferos, construções de loteamentos periféricos em solos frágeis, alterando significativamente características físico-espaciais e socioculturais relevantes na paisagem.

Estudos de Souza (2016) analisaram a dinâmica espacial e temporal do território municipal de São Carlos, considerando quatro tipos de ecossistemas (Fig. 7) e concluem que as três funções ambientais do uso de terra mais afetadas foram: (1) a provisão de recursos abióticos, que correspondem ao papel da mudança no uso da terra que regula a oferta e qualidade de água, ar e minerais, (2) a disponibilização de recursos bióticos, que se relacionam com a capacidade do território em suportar a biodiversidade e (3) a manutenção dos processos ecossistêmicos relacionados com a produção agrícola, ciclagem de nutrientes e formação do solo. 
Figura 7: Dinâmica espacial e temporal do território municipal de São Carlos, SP.
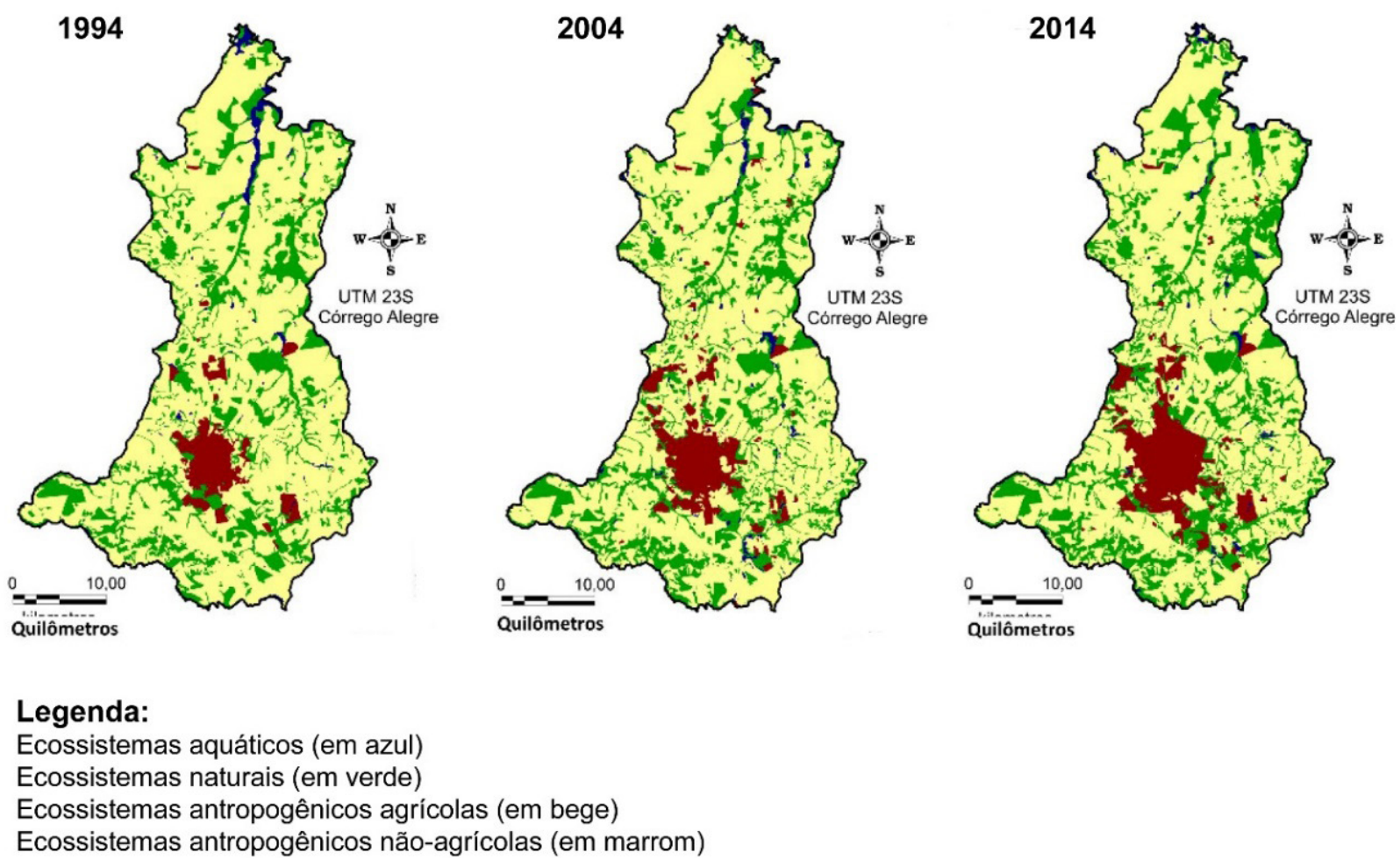

Fonte: SOUZA, 2016.

Destes usos analisados, o que apresentou maior índice de crescimento foi a produção urbana (que apresentou um avanço de quase $10 \%$ em 20 anos), num modelo de crescimento que vem apresentando alterações e tendências, principalmente nas franjas urbanas e periurbanas do território, com novas configurações socioespaciais, principalmente nos últimos 20 anos, como o espraiamento do tecido urbano em direção às bordas periféricas, caracterizado pela descontinuidade territorial, dispersa e fragmentada.

Com o rompimento do padrão 'centro-periferia' que marcou as cidades brasileiras da década de 1980, além dos assentamentos de interesse social, os espaços residenciais murados e controlados destinados à média e alta renda, têm sido o tipo de hábitat de maior consolidação para as franjas da cidade. Porém, diferentemente dos conjuntos populares, os condomínios fechados localizam-se em regiões dotadas de boa urbanização, contemplando equipamentos, serviços e infraestrutura, além de acesso viário com maior mobilidade, resultante de eixos de deslocamento automotivos bem estruturados. Assim, confirmando a tendência, que já vêm sendo analisada em vários estudos socioespaciais em cidades médias paulistas (SPOSITO; GÓES, 2013; OTERO, 2016; BOSCARIOL, 2017), São Carlos vem apresentando um modelo de expansão periférica fragmentado, gerando descontinuidades e vazios urbanos que aguardam as condições mais favoráveis do mercado e reforçam as práticas especulativas.

Essa forma de produção do espaço consolidou dois vetores radicalmente opostos socioespacialmente. Um vetor norte, delimitado por condomínios fechados, articulados ao centro urbano por importantes eixos de circulação, e um vetor sul, com loteamentos 
populares, marcados pela descontinuidade viária e carência de serviços públicos. Na pesquisa de Silva et al. (2015), que abordou as transformações nas dinâmicas socioespaciais nas áreas periféricas de São Carlos, podem ser observadas algumas destas tendências, espacializadas na Figura 8:

Apesar de um aparente compartilhamento dos espaços periféricos, o que a realidade tem mostrado na espacialização dos dados, é uma tendência de polarização entre norte e sul, com a concentração da alta renda na periferia norte e da baixa renda na periferia sul, como polos antagônicos sinalizando os extremos opostos da cidade (SILVA et al., 2015, p.23).

Figura 8: Dinâmicas da expansão urbana de São Carlos, SP.
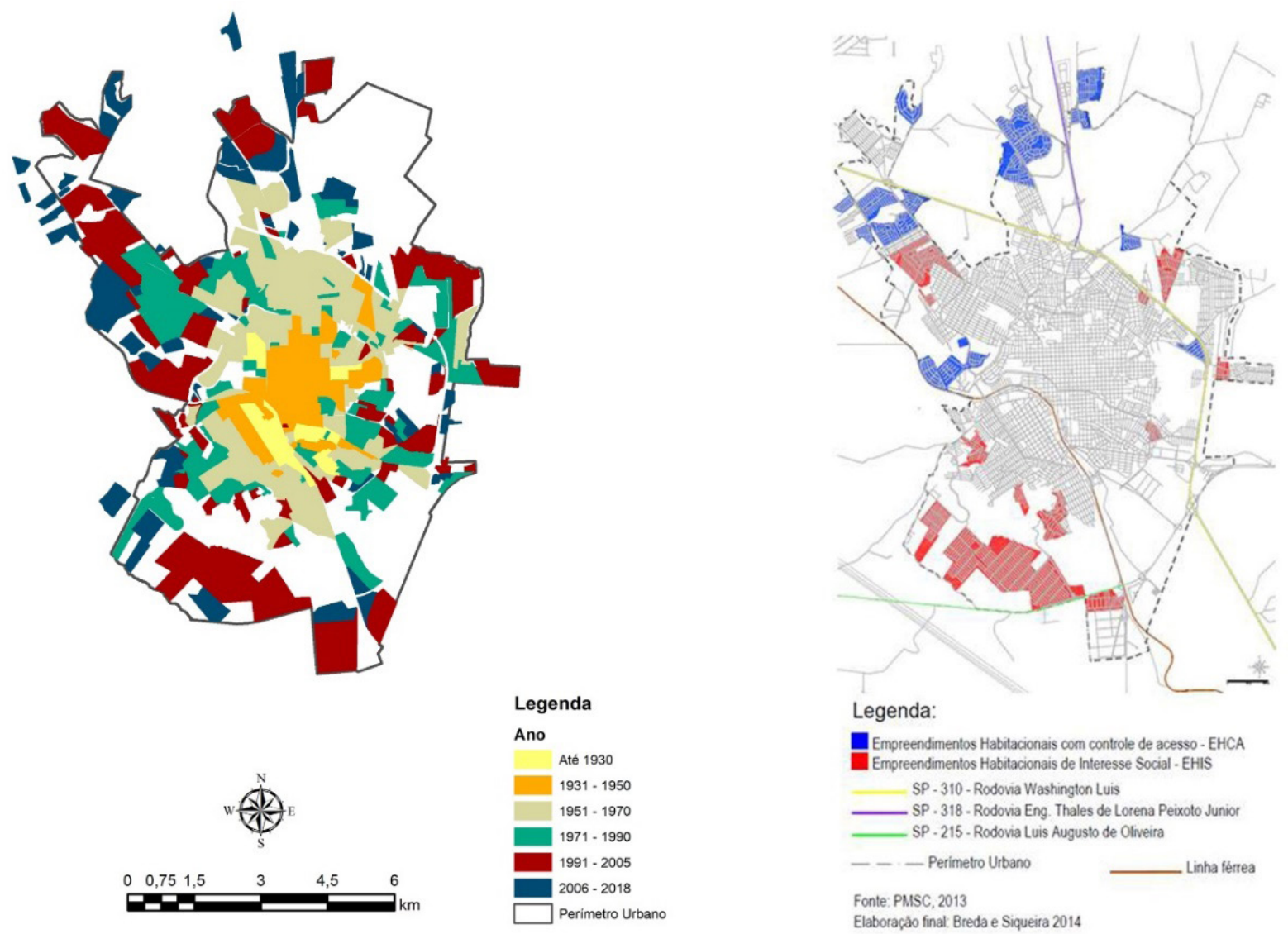

Fonte: LOPES, 2019; SILVA et al., 2015.

Outra nova característica socioespacial, mais afeta aos espaços de transição urbanorural, é a implantação de condomínios de chácaras de recreio que, originalmente se configuravam como segunda moradia para uso de lazer, mas que, atualmente, tornaram a moradia principal de famílias que trabalham em locais próximos aos eixos rodoviários contíguos. Tal configuração demanda um conjunto de estruturas e serviços urbanos, como transporte público, equipamentos coletivos, eixos de mobilidade e acessos viários, novas estações de tratamento de efluentes devido às transposições de bacias hidrográficas, entre outros aspectos, acarretando um ônus público gerado pelo espraiamento do território. 
Análises de SPOSITO e GÓES (2013, pp. 96; 301) sintetizam essas novas tendências que marcam a estruturação de São Carlos, como:

[...] expansão territorial em ritmos mais acentuados que a expansão demográfica; implantação de novos loteamentos e conjuntos habitacionais distantes da área urbana consolidada gerando descontinuidades no tecido urbano, concentração de largas extensões de terras nas franjas de expansão em mãos de grandes incorporadores [...] estando em curso um processo de urbanização difusa, que contribui para a fragmentação e acentua uma nova divisão social do espaço.

As novas configurações dessa 'urbanização difusa', condicionadas pelos aspectos econômicos e fundiários, afetam e interferem diretamente na configuração e na apropriação dos espaços livres urbanos e periurbanos, que em São Carlos, apresentam inúmeros potenciais.

Tentativas de salvaguardar os espaços livres e legitimar seu potencial em instrumentos de planejamento e gestão territorial foram parcialmente reconhecidas e conquistadas no novo Plano Diretor Municipal, sobretudo pela pressão de grupos socioambientais locais. Assim, o Plano criou dois instrumentos de planejamento afetos diretamente aos espaços livres: as Áreas de Interesse Ambiental (AIA) e as Faixas Verdes Complementares (FVC).

As Áreas de Interesse Ambiental (Fig. 9) definem porções do território destinadas a proteger a biodiversidade e promover o uso adequado e sustentável de nascentes, Áreas de Preservação Permanente (APPs), praças, parques, paisagens, encostas e fundos de vale (SÃO CARLOS, 2016, Art.73).

As Faixas Verdes Complementares são áreas contíguas às APPs, com dimensões que variam entre 10, 30 e 50 metros, de acordo com a zona em que estão localizadas e que devem ser previstas nos novos parcelamentos do solo. Têm a finalidade de ampliar a faixa de proteção ambiental dos corpos d'água, incrementar a permeabilidade do solo urbano, servir de suporte para a implantação de mecanismos de retenção de águas pluviais e para a implantação de Parques Lineares (SÃO CARLOS, 2016, Art.137).

Esses dois instrumentos podem ser vistos como importantes mecanismos indutores para a formação de um Sistema de Espaços Livres, porém ainda necessitam de regulamentações específicas, sobretudo no que concerne à definição de diretrizes mais específicas, índices e potenciais usos e espaços a serem conformados em seu interior, além de um desenho que as configure.

Além disso, esses instrumentos não são utilizados pela gestão pública como elementos estruturantes de um planejamento mais integrado no território, que pode ser pensado em escala de bacia hidrográfica e atrelado aos sistemas de mobilidade ou habitacional, por exemplo. Pelo contrário, os processos de aprovação de novos empreendimentos, continuam sendo analisados de forma individual, fragmentada e sem um olhar sistêmico da paisagem. 
Figura 9: Elementos e instrumentos potenciais visando à formação de um Sistema de Espaços Livres em São Carlos, SP.
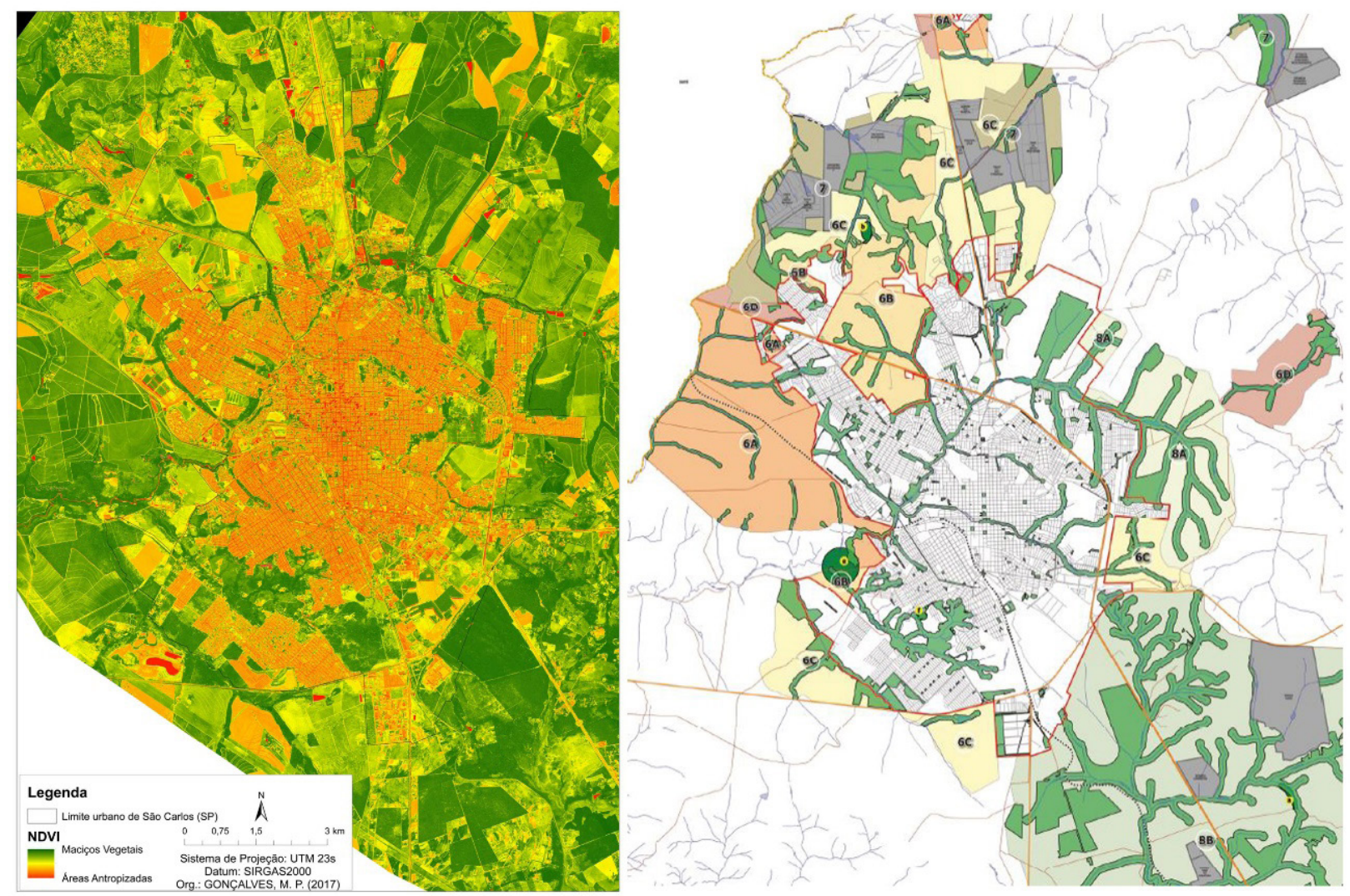

Fonte: GONÇALVES, 2018; SÃO CARLOS, 2016.

Em análise feita nos parcelamentos contíguos aos corpos hídricos (córregos e nascentes), Silva e Bueno (2018) discutem que, embora haja um perceptível avanço no cumprimento à legislação federal no que concerne a reserva das APPs, disciplinadas pelo Código Florestal - Lei Federal 12.651/2012 (BRASIL, 2012), essas áreas não se integram de forma a qualificar a paisagem urbana. Ao examinar um conjunto de projetos de loteamentos aprovados em diferentes décadas, a partir dos anos 1970, até anos mais recentes, observouse que, paulatinamente, os empreendimentos passaram a respeitar a legislação federal, identificando nos projetos as faixas de APPs, muitas vezes assegurando a contiguidade das áreas destinadas ao sistema de lazer. Porém, no geral, nem os órgãos públicos municipais exigem, e nem os projetos dos parcelamentos do solo avançam além da simples demarcação quantitativa desses espaços nas plantas dos projetos.

\section{CONFIGURAÇÃO E GESTÃO DE ESPAÇOS PÚBLICOS INTEGRANTES DA PAISAGEM URBANA}

Nem o Estatuto da Cidade, com força de lei federal, nem os Planos Diretores Municipais, como instrumento básico da política urbana por força constitucional, têm dispositivos adequados ao suprimento de diretrizes ou parâmetros de projeto, enquanto representação 
e desenho, para a cidade que se espalha e que, paulatinamente, se consolida, bem como para a constituição de um Sistema de Espaços Livres. O resultado dessa lacuna tem sido uma morfologia urbana configurada em caráter aleatório e fragmentado, prevalecendo decisões calcadas, sobretudo, nos interesses do mercado imobiliário. Essa distorção tem comprometido a efetividade e a legitimidade de um planejamento urbano sistêmico, ancorado na noção de interesse público.

Apesar de a produção imobiliária da cidade de São Carlos cumprir com a legislação no quesito dotação de áreas públicas, o resultado tem permanecido a sucessiva justaposição desarticulada de pedaços da cidade, que tem caracterizado a maioria das cidades brasileiras. Essa desarticulação formal é, muitas vezes, agravada pela subutilização, ociosidade, falta de manutenção que acarretam problemas de insalubridade, abandono e insegurança urbana, comprometendo a importância da dimensão pública da cidade.

Portanto, trata-se, de duplo desafio a ser enfrentado. Por um lado, o dilema da qualificação da paisagem e das áreas públicas integrantes da cidade já consolidada, frequentemente ociosas, subutilizadas e mal geridas. De outro lado, o desafio da qualificação de áreas potenciais que serão decorrentes dos novos processos de parcelamento do solo nas áreas de expansão da cidade, na híbrida faixa de transição entre o urbano e o rural.

Como alternativa às práticas correntes de produção das cidades no Brasil, Santoro (2012) investigou experiências internacionais. Alemanha, Inglaterra e Espanha, além de planejarem a expansão, exigem percentual de destinação ao uso habitacional. Na Colômbia são empregadas estratégias que articulam o financiamento, a gestão e o planejamento das áreas de expansão. Além do setor privado, o Estado, por meio do poder público local, é o agente promotor da expansão planejada, assumindo a responsabilidade pelos planos e projetos de parcelamento do solo urbano:

Estado urbanizador e construtor de moradias um prol de uma participação maior do setor privado [...] opta-se por uma política pública de urbanização (e não de habitação), admitindo que o estado urbaniza com melhor qualidade e que o privado está tão ou melhor estruturado que o poder público para produzir habitação de forma mais ágil (SANTORO, 2010, p.322).

A participação maior do poder público no planejamento da produção e expansão urbana é uma alternativa bastante desafiadora para os mecanismos de gestão predominantes no Brasil. Essa ação se apresenta como poderoso meio na obtenção de soluções mais articuladas para as áreas públicas decorrentes da ação de se parcelar o solo urbano. O desafio aponta para um conjunto de questões a serem diagnosticadas, debatidas e equacionadas, na perspectiva de superação das limitações observadas, as quais algumas são destacadas neste trabalho, em especial para articulação entre paisagem urbana, espaços públicos e gestão territorial.

A concepção de diferentes configurações com potencial de articulação e integração entre as áreas públicas, e delas com suas áreas envoltórias, envolve o reconhecimento da multiplicidade de contextos envolvidos e as decorrências na posterior gestão de tais espaços. O equacionamento de respostas para esse nível de diversidade de situações 
remete ao desafio de compor mecanismos para diagnosticar, identificar, classificar e propor soluções com flexibilidade adequada às especificidades físico-territoriais, sociais e ambientais envolvidas.

Adicionalmente, a gestão e a manutenção dos espaços públicos existentes e a serem produzidos, integram os desafios presentes na perspectiva de se estabelecer relações que associam esses espaços e o sistema de mobilidade, construindo a morfologia decorrente do arruamento, da composição das quadras e lotes e de suas relações na escala da cidade.

A dinamização de usos nesses espaços e em seu entorno podem potencializar múltiplas apropriações, de acordo com as características de cada local, gerando uma percepção de movimento e fluxo de pessoas, que costuma ser associado a uma maior sensação de segurança. É necessário que haja uma diversidade de usos, e que os lugares sejam frequentados por diferentes públicos e, assim, passam a 'ter olhos' que fazem com que se tornem mais seguros e vivos, gerando na população o sentimento afetivo, para que seja evitado o risco de serem absorvidos ou negados pelos processos de urbanização por serem áreas ociosas ou abandonadas.

Ações educativas, culturais e de mobilização social também podem contribuir com o aumento do conhecimento, da percepção e da identidade da população sobre estas áreas para que, além de preservadas ecologicamente, estas se transformem em efetivos espaços educadores (PERES et al., 2018).

Essas indagações pretendem levantar alternativas para se engendrar cidades abertas, com ruas frequentadas por pedestres, vivas, espaços públicos livres, qualificados, dinamizados pelo uso social de cada contexto.

Representam, assim, um contraponto à tendência de proliferação de espaços isolados, murados, com controle de acesso e desconectados às dinâmicas inerentes à vida pública, $\mathrm{o}$ que subverte o conceito original das cidades como pólis, plural, diversificada e vitalizada pelo uso universalizado de seus espaços.

Assim, uma articulação entre desenho e instrumentos urbanos, sob a ótica da integração entre planejamento da paisagem e planejamento urbano, é urgente e necessária, como defende também Martins (2012):

[...] a perspectiva de traduzir conceitos, hipóteses e princípios subjacentes em desenhos, em forma urbana, para que materializados e visíveis tornem mais fácil avaliar o impacto e o significado formal e ambiental das escolhas de princípios, conceitos e índices urbanísticos é contribuição inadiável (MARTINS, 2012, p.163).

\section{CONSIDERAÇÕES FINAIS}

A discussão das possibilidades de conjugar instrumentos, mecanismos e recursos com potencial para responder os questionamentos aqui apresentados, coloca uma demanda emergencial para o planejamento urbano e a gestão territorial das cidades brasileiras. $\mathrm{O}$ equacionamento dos problemas identificados exige um esforço de avaliação das limitações 
técnicas, legais, institucionais, financeiras e operacionais para enfrentar o desafio de qualificação dos espaços públicos livres de edificações e abertos à utilização.

Primeiramente, o desafio da defesa do protagonismo do poder público, fortalecido como instância planejadora, o que demanda a retomada do papel das administrações públicas municipais, com quadros técnicos preparados e superação de conflitos e integração de decisões intersecretarias. Além destes, outros desafios devem ser superados como: a ruptura com a lógica de descontinuidades de gestão; a urgente organização e atualização de banco de dados físico-territoriais; a instituição de dispositivos legais de regulação das ações governamentais; o equacionamento de eventuais parcerias público-privadas; o estabelecimento de procedimentos técnicos e administrativos adequados; e, a incorporação de demandas da população na promoção de uma gestão democrática e participativa.

Adicionalmente, além dos desafios afetos ao planejamento, há uma relevante limitação a ser equacionada, e que diz respeito à manutenção e gestão desses espaços públicos. Diante as dificuldades de ordem técnica, operacional e financeira, os governos municipais se mostram carentes de meios destinados à gestão e à manutenção desses espaços, até mesmo nos casos em que as áreas públicas sejam pertencentes a setores urbanos centrais e consolidados (RODRIGUES; SILVA; GONÇALVES, 2018).

Nessa esfera de dificuldades, as parcerias com os setores privados e com as próprias comunidades de usuários, devem ser consideradas e debatidas, para que se busquem os meios de viabilização da gestão e da manutenção compartilhada.

Todos esses aspectos devem fazer parte de uma nova cultura de planejamento, que envolva diversos agentes públicos e privados que atuam e interferem na produção da cidade (gestores e técnicos municipais, empreendedores, universidades, sociedade, vereadores, ministério público).

No que tange ao assunto principal desse artigo, o planejamento, consolidação e manutenção de espaços livres e abertos públicos na cidade, o desafio de maior monta diz respeito a uma alteração fundamental na cultura de produção das cidades médias brasileiras.

Provocar o interesse de todos os potenciais envolvidos nessa produção, alterar o registro de seus interesses de uma matriz individualista ou eminentemente econômica estreitada sob a égide do lucro, diz respeito à comunicação e informação de benefícios e custos, e a tomada de decisão à luz de valores para além dos eminentemente econômicos, mas que contemplem questões ambientais, de patrimônio, de memória, estéticas e culturais.

Essa convergência e construção social, que tem na cidade e em sua paisagem seu lugar fundamental, é ação necessária e se faz presente, por exemplo, através do contato entre Universidade e Cidade, processo de encontro e troca que tem em seu horizonte a implantação de um sistema de espaços públicos qualificados e conectados, fruto da integração de processos de planejamento e gestão urbanos: integração entre forma, desenho, instrumentos, legislações e políticas públicas. 


\section{REFERÊNCIAS}

ANDRADE, Thompson A.; SERRA, Rodrigo V. O desempenho das cidades médias no crescimento populacional brasileiro no período de 1970/2000. In: ANDRADE, Thompson A.; SERRA, Rodrigo V. (Orgs.). Cidades médias brasileiras. Rio de Janeiro: IPEA, 2001. p.129-169.

BENEDICT, Mark A.; MCMAHON, Edward T. Green Infrastructure: Linking Landscapes and Communities. Washington, DC: Island Press, 2006.

BOSCARIOL, Renan Amabile. Mercado e moderna incorporação imobiliária nas cidades médias do Oeste Paulista: Araçatuba, Marília, Presidente Prudente e São José do Rio Preto. Brasília, 2017. Tese (Doutorado em Geografia) - Universidade de Brasília, UnB.

BRAGA, Roberto. Política urbana, política fiscal e pacto federativo: limites e perspectivas do Estatuto da Cidade no contexto da reforma do Estado. In: SEMINÁRIO INTERNACIONAL DA REDE IBEROAMERICANA DE INVESTIGADORES SOBRE GLOBALIZAÇÃO E TERRITÓRIO, 7, 2004, Rio de Janeiro, Anais..., Rio de Janeiro: IPPUR-UFRJ, 2004.

BRASIL. Lei ${ }^{0}$ 6.766, de 19 de dezembro de 1979. Dispõe sobre o Parcelamento do Solo Urbano e dá outras Providências. Brasília: Diário Oficial da União, 20 de dezembro de 1979.

BRASIL. Lei $\mathrm{n}^{0}$ 6.938, de 31 de agosto de 1981. Dispõe sobre a Política Nacional do Meio Ambiente, seus fins e mecanismos de formulação e aplicação, e dá outras providências. Brasília: Diário Oficial da União, 2 de setembro de 1981.

BRASIL. Constituição da República Federativa do Brasil de 1988. Brasília, 05 de outubro de 1988.

BRASIL. Lei $\mathbf{n}^{0}$ 9.785, de 29 de janeiro de 1999. Altera o Decreto-Lei $n^{\circ}$ 3.365, de 21 de junho de 1941 (desapropriação por utilidade pública) e as Leis nos 6.015, de 31 de dezembro de 1973 (registros públicos) e 6.766, de 19 de dezembro de 1979 (parcelamento do solo urbano). Brasília: Diário Oficial da União de 01 de fevereiro de 1999 e retificado em 04 de fevereiro de 1999.

BRASIL. Lei $\mathbf{n}^{\circ} \mathbf{1 0 . 2 5 7}$, de 10 de julho de 2001. Regulamenta os arts. 182 e 183 da Constituição Federal, estabelece diretrizes gerais da política urbana e dá outras providências. Brasília: Diário Oficial da União de 11 de julho de 2001.

BRASIL. Lei $\mathbf{n}^{\mathbf{0}} \mathbf{1 2 . 6 5 1}$, de 25 de maio de 2012. Dispõe sobre a proteção da vegetação nativa; altera as Leis $\mathrm{n}^{\circ}$ s 6.938, de 31 de agosto de 1981, 9.393, de 19 de dezembro de 1996, e 11.428, de 22 de dezembro de 2006; revoga as Leis $\mathrm{n}^{\circ} \mathrm{s}$ 4.771, de 15 de setembro de 1965, e 7.754, de 14 de abril de 1989, e a Medida Provisória $\mathrm{n}^{\mathrm{o}}$ 2.166-67, de 24 de agosto de 2001; e dá outras providências. Brasília: Diário Oficial da União de 28 de maio de 2012.

CALDEIRA Teresa P. do Rio. Cidades de muros: crime, segregação e cidadania em São Paulo. São Paulo: Ed. USP, 2000.

CARRUS, Giuseppe; SCOPELLITI, Massimiliano; LAFORTEZZA, Raffaele et al. Go greener, feel better? The positive effects of biodiversity on the well-being of individuals visiting urban and peri-urban green areas. Landscape and Urban Planning, v.134, p. 221-228, 2015. Doi: https://doi.org/10.1016/j. landurbplan.2014.10.022.

CASTELLO BRANCO, Maria Luiza. Cidades médias no Brasil. In: SPOSITO, Eliseu Savério; SPOSITO, Maria Encarnação Beltrão; SOBARZO, Oscar. (Orgs.) Cidades médias: produção do espaço urbano e regional. São Paulo: Expressão Popular, 2006. p.245-277.

DINIZ, Clélio Campolina. Desenvolvimento Poligonal no Brasil: nem desconcentração, nem contínua polarização. Revista Nova Economia, v.31, n.1, p.35-64, 1993.

FAPESP. Terrenos férteis para a inovação. Estudo analisa distribuição de projetos de pequenas empresas de base tecnológica paulistas e aponta São Carlos como o polo mais denso. Boletim Pesquisa Fapesp, n. 246, ago. 2016. Disponível em: http:// pesquisaparainovacao.fapesp.br/sao_carlos_e_principal_polo_de_ empresas_de_base_tecnologica_indica_estudo/13. Acesso em: 7 fev. 2019.

GEHL, Jan. Cidades para pessoas. São Paulo: Perspectiva, 2013. 
GONÇALVES, Monica Palloni. Análise da distribuição espacial, funcionalidade e atratividade de áreas verdes públicas na cidade de São Carlos, SP. São Carlos, 2018. Dissertação (Mestrado em Ciências Ambientais) - Universidade Federal de São Carlos, UFSCar.

HARVEY, David. A produção capitalista do espaço. São Paulo: Annablume, 2005.

IBGE - Instituto Brasileiro de Geografia e Estatística. Informações estatísticas. Cidades paulistas de $100 \mathrm{mil}$ a 500 mil habitantes. 2010. Disponível em: https://cidades.ibge.gov.br/brasil/sp/panorama. Acesso em: 8 fev. 2019.

IBGE - Instituto Brasileiro de Geografia e Estatística. Arranjos populacionais e concentrações urbanas no Brasil. 2.ed. Rio de Janeiro, 2016a. 167p. Coordenação de Geografia. e-Book (PDF). Disponível em: www. ibge.gov.br/apps/arranjos_populacionais/2015. Acesso em: 11 fev. 2019.

IBGE - Instituto Brasileiro de Geografia e Estatística. Brasil: uma visão geográfica e ambiental no início do século XXI. FIGUEIREDO, Adma Hamam de (Org.). Rio de Janeiro: IBGE, 2016b. e-Book. Disponível em: https:/ / biblioteca.ibge.gov.br/visualizacao/livros/liv97884.pdf. Acesso em: 11 fev.2019.

IBGE - Instituto Brasileiro de Geografia e Estatística. Perfil dos Municípios Paulistas. 2019. Disponível em: http://www.perfil.seade.gov.br/. Acesso em: 10 fev. 2019.

JACOBS, Jane. Morte e Vida de Grandes Cidades. 2.ed. São Paulo: Martins Fontes, 2009.

LOPES, Jeniffer Gonçalves. Análise do processo de expansão urbana do município de São Carlos - SP, no período de 2005 a 2018. São Carlos, 2019. Trabalho de Conclusão de Curso (Bacharelado em Gestão e Análise Ambiental) - Universidade Federal de São Carlos, UFSCar.

MACEDO, Sílvio Soares de. Paisagismo brasileiro na virada do século: 1990-2010. São Paulo: Ed. USP/ Ed. Unicamp, 2012.

MACEDO, Sílvio Soares de; CUSTÓDIO, Vanderli; DONOSO, Verônica Garcia (Orgs.). Reflexões sobre espaços livres na forma urbana. São Paulo: FAUUSP, 2018.

MARTINS, Maria Lucia Refinetti. Sociedade e natureza no meio ambiente urbano. In: RIBEIRO, Ana Clara Torres; LIMONAD, Ester; GUSMÃO, Paulo Pereira (Orgs.). Desafios ao Planejamento: produção da metrópole e questões ambientais. Rio de Janeiro: Letra Capital/ ANPUR, 2012. p.154-170.

MAZZUCO, Giulia Guillen; LIONI, Artur Braz; TREVISAN, Diego Peruchi et al. Avaliação da efetividade das políticas públicas voltadas para a proteção das áreas de captação de água: estudo de caso no município de São Carlos-SP. Águas Subterrâneas, v.32, n.1, p.154-161, 2018. Doi: https://doi.org/10.14295/ras. v32i1.28977.

MMA - Ministério do Meio Ambiente. Portaria $\mathbf{n}^{0}$ 223, de 21 de junho de 2016. Reconhece as Áreas Prioritárias para a Conservação, Utilização Sustentável e Repartição de Benefícios da Biodiversidade do Cerrado, do Pantanal e da Caatinga. Brasília: Diário Oficial da União de 22 de junho de 2016.

OTERO, Estevam V. Reestruturação urbana em cidades médias: a cidade como negócio. São Paulo, 2016. Tese (Doutorado em Arquitetura e Urbanismo) - Universidade de São Paulo, FAUUSP.

PERES, Renata Bovo. O Planejamento Regional e Urbano e a Questão Ambiental: Análise da relação entre o Plano de Bacia Hidrográfica Tietê-Jacaré e os Planos Diretores Municipais de Araraquara e São Carlos, SP. São Carlos, 2012. Tese (Doutorado em Engenharia Urbana) - Universidade Federal de São Carlos, UFSCar.

PERES, Renata Bovo; FIGUEIREDO, Andréia Nasser; IARED, Valéria Ghisloti et al. Qualificação de áreas verdes na cidade de São Carlos (SP): análise de usos e propostas de gestão ambiental com foco na Microbacia Hidrográfica do Córrego Santa Maria do Leme. Sociedade \& Natureza, v.30, n.1, p.158-182, 2018. Doi: https://doi.org/10.14393/SN-v30n1-2018-7.

QUAPÁ - Quadro dos Sistemas de Espaços Livres das cidades brasileiras. Imagem aérea produzida na Oficina QUAPA-SEL II. Os Sistemas de Espaços Livres na constituição da forma urbana no Brasil: produção e apropriação. São Carlos, 2014.

RODRIGUES, Felipe Augusto de Sousa; SILVA, Sandra Regina Mota; GONÇALVES, Luciana Márcia. Subsídios para a qualificação dos espaços públicos e abertos, aplicados em praças centrais de São Carlos 
(SP). Cadernos Zygmund Bauman, v.8, n.18, p.131-148, 2018.

RUMBLE, Heather; ANGEOLETTO, Fabio; STUART, Connop et al. Understanding and applying ecological principles in cities. In: LEMES DE OLIVEIRA, Francisco; MELL, I. (Eds.). Planning Cities with Nature: Theories, Strategies and Methods. Amsterdam: Springer Nature, 2019. Chapter 15. p.217-234. Doi: https:// doi.org/10.1007/978-3-030-01866-5_15.

SALDIVA, Paulo. Vida urbana e saúde. São Paulo: Contexto, 2018.

SANTORO, Paula Freire. Planejar a expansão: dilemas e perspectivas. São Paulo, 2012. Tese (Doutorado em Arquitetura e Urbanismo) - Universidade de São Paulo, FAUUSP.

SANTOS, Milton. A urbanização brasileira. São Paulo: HUCITEC, 1996.

SÃO CARLOS (MUNICÍPIO). Lei Municipal no 18.053, de 19 de dezembro de 2016. Estabelece o Plano Diretor do Município de São Carlos e dá outras providências. São Carlos: Diário Oficial do Município, de 28 de dezembro de 2016.

SÃO PAULO (MUNICÍPIO). Lei Municipal no 16.050, de 31 de julho de 2014. Plano Diretor Estratégico do Município de São Paulo - Estratégias Ilustradas. Disponível em: https:/ / gestaourbana.prefeitura.sp.gov. br/marco-regulatorio/plano-diretor/texto-da-lei-ilustrado/. Acessado em: 27 out. 2017.

SCHENK, Luciana Bongiovanni Martins; PERES, Renata Bovo; FANTIN, Marcel. Sistema de espaços livres e sua relação com os agentes públicos e privados na produção da forma urbana de São Carlos, SP. In: MACEDO, Silvio Soares, QUEIROGA, Eugenio F., CAMPOS, Ana Cecília de A., CUSTODIO, Vanderli. (Orgs.) Quadro geral da forma e do sistema de espaços livres das cidades brasileiras. Livro 2. São Paulo: FAUUSP, 2018. p.297-339.

SILVA, Sandra Regina Mota. Transformação das abordagens urbanísticas e ambientais na política territorial brasileira: confluências e divergências no direito de propriedade, nos instrumentos de gestão e no desenho institucional. São Carlos, 2011. Tese (Doutorado em Engenharia Urbana) - Universidade Federal de São Carlos, UFSCar.

SILVA, Sandra Regina Mota; BUENO, Cristiane. Desafios da integração qualificada entre as cidades e seus cursos d' água: configurações das áreas de preservação permanente na cidade de São Carlos (SP), Brasil. In: CONGRESSO LUSO-BRASILEIRO - PLURIS - Cidades e Territórios: desenvolvimento, atratividade e novos desafios, 8, 2018, Coimbra (Portugal). Anais... p. 1158.

SILVA, Sandra Regina Mota; SIQUEIRA, Barbara Vallilo; BREDA, Thalles Vichiato; SILVA, Ricardo Siloto da. Mutações nas dinâmicas socioespaciais das periferias urbanas: reflexos na diversidade urbana e na composição social. UR - Cadernos FA/UL, n.5, p.16-23, 2015.

SOUZA, Imyra Maíra Martins. Mudanças de uso da terra na paisagem cultural. Caso de estudo: município de São Carlos, SP. São Carlos, 2016. Tese (Doutorado em Ciências) - Universidade Federal de São Carlos, UFSCar.

SPIRN, Anne Whiston. O Jardim de Granito. Edusp, São Paulo, 1995.

SPOSITO, Eliseu S. Mercado de trabalho no Brasil e no Estado de São Paulo. In: SPOSITO, Eliseu S.; SPOSITO, Maria Encarnação Beltrão; SOBARZO, Oscar. (Orgs.) Cidades médias: produção do espaço urbano e regional. São Paulo: Expressão Popular, 2006. p.29-46.

SPOSITO, Maria Encarnação Beltrão. Novos conteúdos das periferias urbanas das cidades médias do Estado de São Paulo, Brasil. Investigaciones Geográficas, v.54, p.114-139, 2004.

SPOSITO, Maria Encarnação Beltrão; GÓES, Eda Maria. Espaços fechados e cidades: insegurança urbana e fragmentação socioespacial. São Paulo: Ed. UNESP, 2013.

TERCI, Eliana T.; GOULART, Jefferson O.; OTERO, Estevam V. Dinâmica econômica e empresariamento urbano em cidades médias sob o impacto da reestruturação produtiva. Nova Economia. v.27. n.1. p.143172, 2017. DOI: http:/ / dx.doi.org/10.1590/0103-6351/2825.

TREVISAN, Diego Peruchi. Análise das variáveis ambientais causadas pelas mudanças dos usos e cobertura da terra do município de São Carlos, São Paulo, Brasil. São Carlos, 2015. Dissertação (Mestrado em Ciências Ambientais) - Universidade Federal de São Carlos, UFSCar. 
VASCONCELOS, Pedro Almeida; CORREAA, Roberto Lobato; PINTAUDI, Silvana Maria (Orgs.). A cidade contemporânea: segregação espacial. São Paulo: Contexto, 2013.

VIANA, Sabrina Mieko. Percepção e quantificação das árvores na área urbana do município de São Carlos, SP. Piracicaba, 2013. Tese (Doutorado em Ciências) - Universidade de São Paulo, ESALQ-USP.

WRI BRASIL - World Resources Institute. DOTS nos Planos Diretores: desenvolvimento Orientado ao TransporteSustentável no Planejamento Urbano. Disponível em: https:/ / wribrasil.org.br/pt/publicacoes/ dots-nos-planos-diretores. Acesso em: 15 jul. 2018.

Data de submissão: 22/ fev./ 2019

Data de aceite: 20/ jul./ 2019 